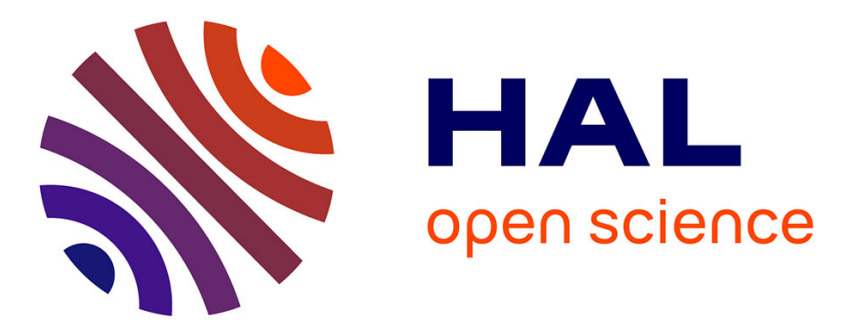

\title{
Development of phonological and orthographic processing in reading aloud, in silent reading, and in spelling: a four-year longitudinal study.
}

Liliane Sprenger-Charolles, Linda S Siegel, Danielle Béchennec, W. Serniclaes

\section{- To cite this version:}

Liliane Sprenger-Charolles, Linda S Siegel, Danielle Béchennec, W. Serniclaes. Development of phonological and orthographic processing in reading aloud, in silent reading, and in spelling: a four-year longitudinal study.. Journal of Experimental Child Psychology, 2003, 84 (3), pp.194-217. hal$00733551 \mathrm{v} 2$

\author{
HAL Id: hal-00733551 \\ https://hal.science/hal-00733551v2
}

Submitted on 24 Sep 2012

HAL is a multi-disciplinary open access archive for the deposit and dissemination of scientific research documents, whether they are published or not. The documents may come from teaching and research institutions in France or abroad, or from public or private research centers.
L'archive ouverte pluridisciplinaire HAL, est destinée au dépôt et à la diffusion de documents scientifiques de niveau recherche, publiés ou non, émanant des établissements d'enseignement et de recherche français ou étrangers, des laboratoires publics ou privés. 
Development of Phonological and Orthographic Processing in Reading Aloud, in Silent Reading and in Spelling: A Four Year Longitudinal Study

Liliane Sprenger-Charolles ${ }^{a}$, Linda S. Siegel ${ }^{b}$, Danielle Béchennec ${ }^{a}$, \& Willy Serniclaes ${ }^{a}$

a. LEAPLE, CNRS \& Université René Descartes, Paris, France; b. University of British Columbia, Vancouver, Canada

Address for correspondence:

Linda S. Siegel

EPSE, 2125 Main Mall

R.Descartes

University of British Columbia

Vancouver, BC V6T 1 Z4

Tel: (604) 8225513

FAX: (604) 8223302

email: linda.siegel@ubc.ca
Liliane Sprenger-Charolles

LEAPLE, CNRS \& Université

7 rue Guy Môquet BP8

94801 Villejuif Cedex, France

Tel: (33) 149583804

FAX: (33) 149583836

email: sprenger@linguist.jussieu.fr

\section{$\underline{\text { Acknowledgement }}$}

We would like to thank two anonymous reviewers for their constructive and helpful suggestions on an earlier version of this manuscript. 


\begin{abstract}
The development of phonological and orthographic processing was studied from the middle of Grade 1 to the end of Grade 4 (age 6; 6 to 10) using the effects of regularity and of lexicality in reading aloud and in spelling tasks, and using the effect of pseudohomophony in a silent reading task. In all the tasks, signs of reliance on phonological processing were found even when indicators of reliance on orthographic processing appeared. Multiple regression analyses were conducted to determine which early skills predict later reading achievement. Pseudoword and irregular word scores were used as measures for phonological and orthographic skills, respectively. Only middle of Grade 1 phonological reading skills accounted for independent variance in end of Grade 4 orthographic skills. Conversely, from the middle to the end of Grade 1, and from the end of Grade 1 to the end of Grade 4, both orthographic and phonological skills accounted for independent variance in later orthographic skills. In the prediction of phonological skills, only the unique contribution of earlier phonological skills was significant. Thus, phonological and orthographic processing appear to be reciprocally related, rather than independent components of written word recognition. However, very early reliance on the phonological procedure seems to be the bootstrapping mechanism for reading acquisition.
\end{abstract}

Key words

Phonological processing, Orthographic processing, Reading acquisition, Spelling acquisition, Lexicality effect, Regularity effect, Pseudohomophony effect 
The objective of this longitudinal study was to examine the development of written word processing in French and to determine which early skills predict later reading achievement. According to the dual-route model, written words can be processed either by an orthographic procedure based on lexical units or by a sublexical phonological procedure based on graphemephoneme correspondences (e.g. Coltheart, Rastle, Perry, Langdon, \& Ziegler, 2001). In this framework, performance on irregular words, which violate the most frequent graphemephoneme correspondences, and on pseudowords, which are not lexical units, are respectively taken as estimates of the efficiency of the orthographic and of the phonological procedures. Developmental models based on this dual-route account of written word processing (Frith, 1986; Morton, 1989) assume that the two procedures are acquired successively, with beginning readers first relying on the phonological procedure and then shifting to the use of an orthographic procedure. However, little is known about the nature of the "bootstrapping" mechanism that permits this shift to occur.

In contrast, within connectionist models (Harm \& Seidenberg, 1999; Plaut, McClelland, Seidenberg, \& Patterson, 1996; Seidenberg \& McClelland, 1989), irregular words and pseudowords are assumed to be read by a single procedure operating over distributed representations of orthographic and phonological units. Such models gradually abstract the statistical relationships between orthographic inputs and phonological outputs; novel words are read through generalization of this knowledge. Similarly, in some developmental models (Ehri, 1998; Perfetti, 1992; Share, 1995), a single procedure - the phonological procedure - is alleged to provide the basic mechanism for acquiring written word knowledge, for regular as well as irregular words.

To assess the early role of the phonological procedure in this acquisition, it is necessary to rely on longitudinal studies, of which there are very few, at least in languages other than English. In addition, if the phonological procedure plays a significant role in reading acquisition, this acquisition should be influenced by the degree of consistency of the grapheme-phoneme correspondences in a given language. Compared to English, grapheme-phoneme correspondences are more consistent in French (Peereman \& Content, 1999; see also Ziegler, 
Jacobs, \& Stone, 1996; Ziegler, Stone, \& Jacobs, 1997). This grapheme-phoneme consistency should be reflected in French reading acquisition. Thus, reading acquisition should be assessed in French. However, in French, phoneme-grapheme correspondences are less consistent than grapheme-phoneme correspondences (Peereman \& Content, 1999). It is therefore important to examine reading acquisition together with spelling acquisition. Furthermore, most of the studies on reading acquisition have been based on tasks such as reading aloud that force the child to pronounce the word and therefore to contend with its phonological properties, which is not the case in silent reading. Thus, effects of the phonological properties of items in tasks that theoretically could be solved on the sole basis of visual codes could be taken as an indicator of a mandatory involvement of phonological processing in written word processing (see Olson, Forsberg, Wise, \& Rack, 1994).

In consideration of these issues, we conducted a long-term longitudinal study relying on a battery that included reading aloud, silent reading and spelling tasks, in order to examine the development of written word processing in French and to determine which early skills predict later achievement.

\subsubsection{Previous Tests on the Critical Assumptions}

Most studies on reading and/or spelling acquisition have relied on the basic tenets of the dual-route model. Therefore, in reading aloud or in spelling, the presence of effects of frequency and of lexicality without any regularity effect is assumed to reveal the use of an orthographic procedure; the reverse trend, a regularity effect without any effect of frequency or of lexicality, would indicate reliance on the phonological procedure. In silent reading tasks, such as lexical decision or semantic categorization, a higher number of false positive responses on homophone or on pseudohomophones (i.e. pseudowords which sound like real words) than on control foils, is interpreted as an indicator of reliance on the phonological procedure.

In this framework, the fact that beginning readers rely primarily on phonological processing seems well established, both for reading aloud (in English, Backman, Bruck, Hebert, \& Seidenberg, 1984; Waters, Seidenberg, \& Bruck, 1984; in German, Wimmer \& Hummer, 1990; 
in French, Leybaert \& Content, 1995; Sprenger-Charolles, Siegel, \& Bonnet, 1998b) and for silent reading tasks (in English, Doctor \& Coltheart, 1980; in Dutch, Bosman \& de Groot 1996; in French, Sprenger-Charolles, Siegel, \& Béchennec, 1998a). The results also indicate that this procedure may be gradually replaced by an orthographic procedure (for reading aloud in English, Backman et al., 1984; Seidenberg, Waters, Barnes, \& Tanenhaus, 1984; Waters et al., 1984; in French, Sprenger-Charolles et al. 1998b; for silent reading tasks, Coltheart, Laxon, Rickard, \& Elton, 1988; Johnston, Thompson, Fletcher-Flinn, \& Holligan, 1995). In addition, less reliance on phonological processing has been reported in children who first learn to read in English compared to children whose native language is Spanish, German or French (for a review, see Sprenger-Charolles, 2003), suggesting that the transparency of the written system influences reading acquisition.

Reading and spelling acquisition were investigated together in English (Bruck \& Waters, 1988; Foorman, Jenkins, \& Francis, 1993; Foorman, Novy, Francis, \& Liberman, 1991; Juel, 1988; Juel, Griffith, \& Gough, 1986; Stage \& Wagner, 1992; Waters, Bruck, \& Seidenberg, 1985;), in German (Wimmer \& Hummer, 1990) and in French (Leybaert \& Content, 1995; Sprenger-Charolles \& Casalis, 1995; Sprenger-Charolles et al., 1998b). In these studies, spelling was found to be more difficult than reading. However, a similar pattern for the regularity effect was observed in reading and in spelling (Bruck \& Waters, 1988; Foorman et al., 1991, 1993; Sprenger-Charolles et al., 1998b) and correlational analyses have shown strong relationships between these two skills (e.g., Juel, 1988; Juel et al., 1986; Stage \& Wagner, 1992; Sprenger-Charolles et al., 1998b), thus suggesting a similar development.

Reading aloud and silent reading tasks were both used in a recent cross-linguistic study (Goswami, Ziegler, Dalton, \& Schneider, 2001). Differences were found in the processing of pseudohomophones depending on the task (reading aloud or silent reading) and on the degree of opaqueness of grapheme-phoneme correspondences (English versus German). In the reading aloud task, the German-speaking children read the pseudohomophones just as well as they read the control pseudowords, and with a very high level of accuracy. The level of accuracy of the English-speaking children was lower, particularly for the non-homophone 
pseudowords. In silent reading - a lexical decision task - a pseudohomophone disadvantage was observed in only the German-speaking children. These results suggest that for the German-speaking children, but not for the English-speaking children, the activation of phonological information is rather automatic and difficult to inhibit. Thus, in languages with a transparent orthography, the involvement of the phonological procedure in written word processing could be mandatory ${ }^{1}$.

Some of these studies relied on only one assessment at one point in the development of reading (Bosman \& de Groot, 1996; Waters et al., 1984; Wimmer \& Hummer, 1990), some only on a short-term longitudinal assessment (Foorman et al., 1991; Juel et al., 1986; SprengerCharolles \& Casalis, 1995; Sprenger-Charolles et al, 1998a and b), and some were crosssectional (Backman et al., 1984; Bruck \& Waters, 1988; Coltheart et al., 1988; Doctor \& Coltheart, 1980; Foorman et al., 1993; Goswami et al., 2001; Johnston et al., 1995; Leybaert \& Content, 1995; Stage \& Wagner, 1992; Waters et al., 1985). In addition, most studies assessed the development of reading and/or of spelling skills only after the first grade, and not at the very beginning of acquisition (for example, Backman et al., 1984; Leybaert \& Content, 1995; Waters et al., 1984, 1985). Consequently, they could not determine the weight and the role of very early phonological skills in the development of later written word processing.

Some short-term longitudinal data have shown phonological processing to contribute to the construction of the orthographic lexicon. For example, in a very early stage of acquisition, children who were unable to decode even very simple words were able to learn to associate target words with phonological cues more easily than with visual cues (Ehri \& Wilce, 1985; L aing \& Hulme, 1999; Rack, Hulme, Snowling, \& Wigham, 1994). Similarly, in a two-year follow-up study, early phonological skills were found to capture most of the unique variance in written word identification (Manis, Custodio, \& Szeszulski, 1993). Additional evidence of the role of phonological mediation has been provided by Byrne, Freebody and Gates (1992) with a comparison between "Chinese" and "Phoenician" readers. The first group was characterized by a large reliance on orthographic processing and the second by the use of more efficient phonological processing. Between sessions, the reading level of "Phoenician" readers 
improved (including reading irregular words), while deterioration in word reading skills was observed for the "Chinese" readers. Finally, in a short-term longitudinal study of Frenchspeaking children (Sprenger-Charolles et al., 1998b), early phonological skills, as evaluated in the middle of the first grade by pseudoword processing, were found to be correlated with performance on irregular words at the end of the same grade, whereas the reverse was not observed in either reading or in spelling. Effective phonological processing in the early stages of reading acquisition seemed thus to facilitate the construction of the orthographic lexicon, at least at the beginning of acquisition.

A more direct test of the hypothesis that phonological skills are critical to the acquisition of word specific orthographic representations has been provided by Share (1999). This research was conducted in Hebrew, which is considered to have near perfect one-to-one letter-sound correspondences when pointed (written with all the vowels). The experimental paradigm consisted of multiple presentations of target words embedded in short texts to second graders; the targets were pseudowords representing fictitious names for cities, animals, flowers, and the like. Three days later, each child was asked if he/she remembered the story and was presented with four alternative spellings of the target item (the original target spelling, a homophonic foil, a visually similar foil with a letter substitution and one with a transposition of two letters). Target spellings were correctly identified more often, named more quickly and spelled more accurately than even the homophonic foils (Experiment 1). However, conditions designed to minimize phonological processing (for example, irrelevant concurrent vocalization, Experiment 2), significantly reduced the degree of orthographic learning. The contribution of pure visual exposure (non-alphabetic symbols replacing the original Hebrew letters in the target words, Experiment 4) was found to be very small. It would appear that even in a very transparent orthography, "phonological recoding may well represent the cutting edge of reading development not merely for the beginner, but throughout the entire ability range" (Share, 1999, p. 97). However, this study did not account for the beginning of reading acquisition (only second graders were involved) and was conducted on a very short-term basis. 
Although all of the studies just described suggest the importance of phonological processing in the construction of the orthographic lexicon, they suffer from limitations, largely because they are short-term studies and/or do not examine the very beginning of reading-spelling acquisition. For that reason, we chose the the middle of Grade 1 as a beginning point, after four months of reading instruction, to avoid significant floor effects and the end of Grade 4 as an end point, when the orthographic lexicon is assumed to be sufficiently mature..

\subsubsection{Overview of the Present Study}

In consideration of the issues described above, the development of phonological and orthographic processing in French was assessed from the middle of Grade 1 to the end of Grade 4. Our hypotheses were, firstly, that as the orthographic lexicon cannot be constructed before the beginning of reading and spelling acquisition, phonological processing would be more significant than orthographic processing in the beginning of acquisition; secondly, because of the progressive construction of the orthographic lexicon, the reverse trend would be expected for later stages; and thirdly, that reliance on phonological processing may be the bootstrapping mechanism for the acquisition of word specific orthographic representations. In reading aloud and in spelling, effects of regularity ${ }^{2}$ and of lexicality were taken as estimates of reliance on phonological or orthographic processing, respectively. In silent reading, we used a semantic categorization task in which we manipulated the effect of pseudohomophony. To verify whether the children were familiar with the correct spelling of the word from which the pseudohomophones were derived, we relied on an orthographic choice task. Multiple regression analyses were conducted to examine the third hypothesis.

\section{METHOD}

\section{Participants}

The children were recruited from seven kindergarten classes selected from various suburbs of Paris. Only the sixty children who met the following criteria were enrolled ${ }^{3}$ : French as native language, no language or motor problems or psychological difficulties according to the teachers 
or school psychologists, average or above average non-verbal and verbal IQ scores, unable to read at the end of kindergarten. In first grade, the children were in 20 different classes, in 9 primary schools. Children were sampled from many classes so that the probability of teacher and teaching method effects was greatly reduced. In addition, the teaching methods used in Grade 1 in these schools, as in most French schools (see Béchennec \& Sprenger-Charolles, 1998), mixed the "analytical" approach (focusing on simple vowels and consonants in syllables and words) and the "global method" (use of key words and short texts). At the end of Grade 4, 42 children remained (26 males and 16 females, mean age $=9 ; 11, \underline{S D}=4$ months).

While in kindergarten, the children's nonverbal IQ was assessed with Raven's matrices (Raven, 1981). Verbal IQ was measured with an oral French vocabulary test designed for 5- to 8-year-olds (Deltour \& Hupkens, 1980). The mean scores obtained by the children in kindergarten in the Raven's matrices and in the vocabulary tests were respectively 17.1 (out of $36, \underline{S D}=3.17$ ) and 40.6 (out of $60, \underline{S D}=5.41$ ). The Bat-Elem reading test (Savigny, 1974), a standardized test for first to third grade (ages 6-9) was also administered at the end of kindergarten. Only the children who read less than 5 of the 10 first items in the test (i, o, u, é, bi, ra, né, ou, oi, fin) were included in the study.

\section{Tasks and Procedure}

Reading Aloud and Spelling Tasks. A word was defined as regular if it contained only high frequency grapheme-phoneme correspondences (Catach, 1980). A word was defined as irregular if it contained either a low frequency grapheme-phoneme correspondence or a silent grapheme ${ }^{4}$. Three levels of regularity had been defined in the regular words, corresponding to the main features of French orthography. The first level items consisted of only one-letter graphemes. The second-level items included context-independent two-letter graphemes ("ou" and "ch", chosen because they have no other frequent alternative spelling and should therefore not be more difficult to spell than to read, unlike the bigraph "au", always read /O/, although /O/ can be written "o", "au" or "eau"). The third-level items included context-dependent graphemes ("c" and "g"). All words (regular and irregular) were listed in the Listes Orthographiques de 
Base (Catach, 1984) or in the Dictionnaire Fondamental (Gougenheim, Michéa, Rivenc, \& Sauvageot, 1964) in which the most frequent French words are given ${ }^{5}$. Pseudowords, matched with the regular words of the three levels of grapheme-phoneme regularity, were created in such a way that they contained only digraphs or trigraphs commonly found in French and shared no analogical relations with real words (i.e., the pseudowords did not share the same beginnings or endings as common French words). The mean trigraph frequency for the regular words, the irregular words and the pseudowords was respectively, 265, 221, 72 (Content \& Radeau, 1988). For each category, the test items were matched in number of letters and syllables and, because time latencies were examined, according to the phoneme corresponding to their first grapheme. The stimuli are shown in the appendix.

The reading and spelling tasks were administered in the middle of Grade 1 and at the end of Grades 1, 2, 3, and 4. Children were tested individually, except for the spelling tests, in a quiet classroom. Before each test, practice items were given. No feedback was provided during the tests. The word list was presented before the pseudoword list for both reading and spelling tasks. Each list contained items from each category in a random order. For the two first test sessions, only the regular words and the pseudowords corresponding to the first two levels of regularity were presented, third-level items being added in the subsequent test sessions. The reading tasks were administered before the spelling tasks to prevent the children from having an auditory image of the items before the reading task. To be scored as correct, the words had to be read or spelled exactly and the pseudowords to be read or spelled according to the French grapheme-phoneme or phoneme-grapheme correspondences. Due to the asymmetry between grapheme-phoneme and phoneme-grapheme correspondences, more than one spelling is acceptable for the pseudowords, but not for the regular words. For example, the grapheme "c" in the pseudoword "tocir", and in the word "facile", can only be read /S/, while it can be spelled "c" or "ss"; therefore, two spellings are acceptable for the pseudoword /TOSIR/ ("tocir", and "tossir"), but only one for the word /FASIL/.

The reading tasks were administered on a computer. The child was asked to read aloud each item that appeared on the monitor. Correct responses as well as mispronunciations were 
recorded by the tester during each test session and were later reexamined using computer recordings to verify each response and to calculate correct response time latencies by the means of the speech signal edited by a speech signal editor. The recording began when the stimulus appeared on the monitor. Processing time was calculated from stimulus onset to the beginning of the first speech signal corresponding to the response. Latencies were not taken into account when they exceeded more than three standard deviations of the mean for each child in each category of items in the different test sessions (between $2 \%$ and $3 \%$ of the data) and were only analyzed when more than $50 \%$ of the responses were correct. For the spelling tasks, isolated test items were dictated to small groups of children. Because of the risk of confusion between homophones, the words were first read in a sentence.

Semantic Categorization Task. Pseudohomophones and visual foils were pseudowords derived from high frequency words such as "rouge" [red], "auto" [car]. The pseudohomophones ("rouje", "oto") were homophones of the correct words spelled with one letter added or omitted ("oto" instead of "auto"), except for "rouje", in which the letter "g" was replaced by "j". The visual foils ("rouqe", "outo") had the same number of letters as the correct word, and differed only by one letter which was visually similar to the correct one; for that, we used a font specially designed for the experiment (for example, the letter "a" was a circle with a vertical bar on the right side). The shape of the words was, therefore, less well preserved in the pseudohomophones than in the visual foils. Each word was altered in the same place for both types of foils: at the beginning (e.g. "oto" or "outo" instead of "auto"), at the end (e.g. "rouje" or "rouqe" instead of "rouge"), or in the middle (e.g. "carote" or "caratte" instead of "carotte"). The mean trigraph frequency of each type of foil was similar (89 for the pseudohomophones and 101 for the visual foils, Content \& Radeau, 1988). The experimental list of pseudowords included, as fillers, correct words with approximately the same characteristics (frequency, length, spelling pattern) as the correct words used to construct the experimental foils.

The children saw the pseudohomophones and the visual foils of a particular word in two different lists. The first contained half the fillers (correct words) and half of each kind of foils (e.g., "oto" and "rouqe"); the second list contained the rest of the fillers and the rest of the foils 
(e.g., "outo" and "rouje"). The order in which they were presented was counterbalanced and the two presentations were separated by at least one day. The task was administered to the children individually on a computer. The children were required to judge whether the target item was an exemplar of a particular semantic category. For example, the voice on the computer asked, "Is it an animal?" and subsequently the item appeared on the screen. The children replied by pressing specific keys on the keyboard. Familiarization trials were given before the test. No feedback was provided during the practice or during the test. The children were administered this test in the middle of Grade 1 and at the end of Grades 1, 2, 3 and 4. Accuracy and processing time (for correct responses only) were recorded. Timed responses exceeding three standard deviations of the mean of each child in each category of items were deleted (less than $3 \%$ of the data).

Orthographic Choice Task. The test items were the same as in the semantic categorization task, but the correct word was provided together with the two foils. Each set of three items was presented on a single line, the presentation order being randomly assigned from one set to the other. The children were instructed to select the correct spelling of the word. This task was administered at each of the five sessions, after the semantic categorization task.

\section{RESULTS}

\section{Reading Aloud and Spelling Tasks}

According to the first hypothesis, at the beginning of reading and spelling acquisition, we expected an effect of regularity (significant differences between regular and irregular words) but no effect of lexicality (no differences between regular words and pseudowords). Theoretically, the pseudowords used in this study could only be processed by the phonological procedure, especially as they were not analogous to frequent words. Irregular words will be read incorrectly using this phonological procedure. Therefore, the regularity effect was expected to surpass the lexicality effect resulting in better processing of pseudowords than of irregular words. According to the second hypothesis, the regularity effect was supposed to decrease 
from the beginning to the end of the study and the lexicality effect was expected to appear and even to surpass the regularity effect when irregular words were compared to pseudowords.

The results for accuracy in reading aloud and in spelling are shown in Table 1. For each task, an ANOVA was conducted on the factors Type of item (3 levels: Regular word, Irregular word and Pseudoword) and Grade (5 levels: middle and end of Grade 1, end of Grades 2, 3 and 4). For the reading task, we observed significant effects of Grade, $\underline{F}(4,164)=221.2, \underline{p}<.01$, and of Type of item, $\underline{F}(2,82)=207.2, \underline{p}<.01$. The interaction between these factors, $\underline{F}(8$, $328)=30.1, \underline{p}<.01$, reflects the fact that the children were always more accurate on regular words than on pseudowords, except in the first session, and that they reached a high level of accuracy very rapidly on regular words (by the end of Grade 1), but much more slowly on irregular words. In fact, a long lasting regularity effect was found, irregular words always being read less accurately than both regular words (middle and end of Grade 1, end of Grades 2, 3 and 4 , respectively, $\underline{F}(1,41)=77.2 ; 167.2 ; 96.1 ; 56.7 ; 25.6$; all $\underline{p s}<.01)$ and pseudowords, except in the last test session (middle and end of Grade 1, end of Grades 2 and 3, respectively, $\underline{F}(1,41)=86.8 ; 77.8 ; 23.3 ; 7.56 ;$ all $\underline{p s}<.01$; end of Grade $4, F<1)$. Whereas irregular words were never read more accurately than pseudowords, regular words were always read more accurately than pseudowords (end of Grades $1,2,3$ and 4 respectively, $\underline{F}(1,41)=32.6 ; 30.2$; 16.8; 19.8; all $\underline{p s}<.01)$, except in the first test session, $\underline{F}(1,41)=3.9, \underline{p}<.052$.

In the spelling tasks, we observed a significant effect of Grade, $\underline{F}(4,164)=215.2, p<.01$, and of Type of item, $\underline{F}(2,82)=359.9, p<.01$. The interaction between these factors, $\underline{F}(8$, $328)=23.3, p<.01$, may be explained by the differences between irregular words versus regular items (words or pseudowords) first increasing and then decreasing. However, irregular words were always spelled less accurately than both regular words (respectively for middle and end of Grade 1, end of Grades 2, 3 and 4, $\underline{F}(1,41)=60.9 ; 354.7 ; 339.5 ; 98.2 ; 42.2$; all $\underline{p s}<$ .01 ) and pseudowords (middle and end of Grade 1, end of Grades 2, 3 and 4, $\underline{F}(1,41)=75.1$; 276.0; 313.5; 92.9; 35.1; all ps < .01). The comparison between irregular words and pseudowords thus indicated that the lexicality effect never favors word spelling. Similarly, regular words were never spelled more accurately than pseudowords, the latter even being 
spelled more accurately in the middle of Grade 1 and at the end of Grade 2, respectively, $\underline{\mathrm{F}}$ (1, 41) $=4.4, \underline{\mathrm{p}}<.05 ; 12.5, \underline{\mathrm{p}}<.01$.

Insert Table 1 about here

Reading latencies were only taken into account from the end of Grade 2, because at the end of Grade 1, too many children produced fewer than $50 \%$ correct responses ( 25 children out of 42 for irregular words, 3 for regular words and 5 for pseudowords) ${ }^{6}$. The ANOVA was conducted based on two factors, Grade (3 levels: Grades 2, 3 and 4) and Type of item (3 levels: Pseudoword, Irregular word and Regular word). The results are shown in Table 2. There was an effect of Grade, $\underline{F}(2,82)=35.0$, $\underline{p}<.01$, of Type of item, $\underline{F}(2,41)=33.8, \underline{p}<.01$, and an interaction between these factors, $\underline{F}(4,164)=4.1, \underline{p}<.01$. At the end of Grade 2 , regular words were read more rapidly than both irregular words, $\underline{F}(1,41)=5.7, \underline{p}<.05$, and pseudowords, $\underline{\mathrm{F}}(1,41)=5.4, \underline{\mathrm{p}}<.05$, the last two types of items being read at the same speed. At the end of Grades 3 and 4, no significant differences were found between regular and irregular words, whereas pseudowords were read less rapidly than both regular words, $\underline{F}(1,41)$ $=34.5$ and 64.6, $\underline{\mathrm{p}}<.01$, and irregular words, $\underline{\mathrm{F}}(1,41)=31.2$ and $52.7, \underline{\mathrm{p}}<.01$.

Insert Table 2 about here

In summary, in the first grade, the only finding contradicting the first hypothesis was the lexicality effect found in the reading task at the end of Grade 1 when regular words were compared to pseudowords. The second hypothesis was not supported by the results of the spelling tasks. In the reading tasks, the results were less clear-cut when accuracy and latencies were both taken into account. The expected fading of the regularity effect was noted only in latencies and only from the end of Grade 3 whereas the expected emergence of the lexicality effect was observed very early in the comparison between regular words and pseudowords, both according to accuracy scores (end of Grade 1) and latencies (end of Grade 2). In the 
comparison between irregular words and pseudowords, the lexicality effect was found to surpass the regularity effect, but only from the end of Grade 3 and only according to latencies.

\section{$\underline{\text { Silent reading tasks }}$}

The effect of pseudohomophony was taken as an estimate of reliance on the phonological procedure. Therefore, according to the first hypothesis, the number of correct rejections of pseudohomophones was expected to be significantly lower than that of visual foils at the beginning of reading acquisition and, according to the second hypothesis, this effect should progressively disappear.

Accuracy scores for the semantic categorization task are shown in Table 3. The ANOVA was conducted based on two factors, Type of foil (2 levels, pseudohomophones and visual foils) and Grade (5 levels: middle and end of Grade 1, end of Grades 2, 3 and 4). Performance improved between Grades, $\underline{F}(4,164)=91.52, \underline{p}<.01$, and pseudohomophones led to fewer correct responses than visual foils, $\underline{F}(1,41)=117.3, \underline{p}<.01$. The Type of foil $x$ Grade interaction was significant, $\underline{F}(4,164)=8.4, \underline{p}<.01$. Performance on the two types of foils was comparable in the middle of Grade 1, but thereafter was more accurate for visual foils than for pseudohomophones (end of Grade 1, 2, 3 and 4; $\underline{F}(1,41)=32.8 ; 55.4 ; 37.6$ and 10.1, all $\underline{p s}<$ .01). Latencies were only considered for the last test session ${ }^{6}$, accuracy scores being too low in previous sessions, particularly for pseudohomophones. Pseudohomophones were correctly rejected more rapidly $(1646 \mathrm{~ms} . \underline{\mathrm{SD}}=482)$ than visual foils $(1807 \mathrm{~ms}$., $\underline{\mathrm{SD}}=624)$. According to the ANOVA, conducted based on the factor Type of foil, the difference was significant, $\underline{F}(1,41)$ $=6.16, \mathrm{p}<.03$.

Insert Table 3

For the Orthographic Choice Task, the ANOVA was conducted on the factor Grade (5 levels: middle and end of Grade 1, end of Grades 2, 3 and 4). Accuracy scores increased with Grade, $F(4,164)=152.02, p<.01$, but the increase was significant only between the middle of Grade 
1 and the end of Grade 2 (respectively middle versus end of Grade 1, end of Grade 1 versus end of Grade 2, F $(1,41)=62.87$ and 70.24 , all ps $<.01)$, no later, probably because of ceiling effects. Because the children's orthographic lexicon seemed quite well established at the end of Grade 2, at least for the items chosen for this study, the results of the semantic task were apparently not due to imprecise orthographic knowledge.

In summary, with the exception of the finding that pseudohomophones were not selected more often than visual foils in the middle of Grade 1, the other results are in agreement with the first hypothesis and suggest that, in the first grade, children relied mainly on phonological skills. From the end of Grade 1, as the pseudohomophones were incorrectly accepted more often than the visual foils, the phonological features of the items seem to have a long lasting influence on the performance of the children, which is in contradiction to the second hypothesis. The second hypothesis is, however, supported by the fact that, according to the latencies, the pseudohomophones were more rapidly rejected than the visual foils in the last test session.

\section{$\underline{\text { Regression Analyses }}$}

Regression analyses were conducted to test the hypothesis that early phonological reading skills contributed to later orthographic skills and the same regression analyses were also conducted for the prediction of later phonological skills. We first examined whether variance in later orthographic skills could be predicted by variations in prior phonological skills and, secondly, whether variance in later phonological skills could be predicted by variations in prior orthographic skills. Pseudoword and irregular word scores were used as measures for phonological and orthographic skills respectively. We first compared data from the middle of Grade 1 to the data observed at the end of Grades 1 and 4 . We then compared the data from the end of Grade 1 to the data observed at the end of Grade 4. We also took into account the level of verbal and non-verbal IQ scores before the beginning of reading acquisition ${ }^{7}$. We relied on the same pseudowords and irregular words as those in the reading aloud tasks, but only for accuracy scores; latencies are not reliable when the level of accuracy is too low, as in the beginning of this study. 
As Table 4 shows, none of the correlations of IQ scores with later reading performance were significant. The middle of Grade 1 pseudoword scores were correlated with all the scores at the end of Grades 1 and 4, whereas the middle of Grade 1 irregular word scores were only correlated with the irregular word scores at the end of the same grade. Conversely, by the end of Grade 1, all of the correlations with the end of Grade 4 were strong.

Insert Table 4 about here

For the regression analyses, since IQ was not significantly correlated with later reading scores, this variable was not entered in the model. Commonality analyses were conducted to determine the amount of shared and unique variance between the variables. In such analyses the increase in variance associated with the last variable entered in the regression analyses represents the unique contribution of that variable (see Manis, Seidenberg, \& Doi, 1999). Table 5 presents the contribution of shared and unique pseudoword and irregular word scores as predictors of either later irregular word scores, or later pseudowords scores. The unique contribution of pseudoword scores was always significant. Conversely, the unique contribution of irregular word scores was significant only in the prediction of irregular word scores and only in two out of three cases. More precisely, in the prediction of the irregular word scores at the end of Grade 1, the unique contribution of both earlier irregular word scores and earlier pseudoword scores was significant (respectively, $10.4 \%$ and 12\%). Much the same pattern of results was found for the irregular word scores at the end of Grade 4 as predicted by the end of Grade 1 scores $(7.7 \%$ for irregular words and $7.2 \%$ for pseudowords). Conversely, when taking the data of the middle of Grade 1 into account in predicting irregular word scores at the end of Grade 4, the unique contribution of pseudoword scores was significant $(9.6 \%)$, while the unique contribution of irregular word scores was not (1.2\%).

In the prediction of pseudoword scores at the end of Grade 1 and Grade 4, only the unique contribution of earlier pseudoword scores was significant. However, this contribution was larger in the short-term than in the long-term: $27.4 \%$ from the middle to the end of Grade $1,18.3 \%$ 
from the end of Grade 1 to the end of Grade 4, 10.1\% from the middle of Grade 1 to the end of Grade 4.

Insert Table 5 about here

In summary, from the middle to the end of Grade 1, and from the end of this grade to the end of Grade 4, orthographic skills and phonological skills predicted later orthographic skills. Conversely, from the middle of Grade 1 to the end of the study, only phonological skills significantly contributed to later orthographic skills. In addition, later phonological skills were only explained by earlier phonological skills. These results suggest that very early reliance on phonological processing is a powerful generative mechanism, the efficiency of which is the unique predictor of long-term reading skills, including orthographic skills. These results are consistent with the third hypothesis.

\section{DISCUSSION}

\section{Development of Reading and Spelling Skills}

Early Development of Phonological and Orthographic Skills. In agreement with the first hypothesis, phonological processing seems to be more significant than orthographic processing in the early stages of reading-spelling acquisition. This was indicated, first, by the pseudohomophony effect observed in the semantic categorization task; second, by the regularity effect noted both in reading and in spelling; and third, by words not being better read or spelled than pseudowords. Two contradictory findings were noted. Firstly, no significant pseudohomophony effect was observed in the middle of Grade 1 in the semantic task, but this could be due to very early readers primarily accepting what was written as correct, thus casting doubt on the validity of such a task in the very beginning of reading acquisition. Secondly, in the reading aloud task at the end of Grade 1, a lexicality effect was noted in the comparison between regular words and pseudowords, probably because of regular frequent words benefiting from both a word frequency and a grapheme-phoneme regularity advantage, while 
pseudowords benefited from only one of these effects. Except for the last two results, all the others were consistent with the first hypothesis. They reproduced the results already published on the effect of regularity and lexicality in reading aloud and in spelling in first grade (with 57 children of the same cohort, Sprenger-Charolles et al., 1998b) and on the effect of pseudohomophony in silent reading (with 48 children of the same cohort, Sprenger-Charolles et al., 1998a). They indicated that reliance on phonological processing appeared not to decline even when some signs of the construction of the orthographic lexicon were observed. Thus, rather than being independent components of written word recognition, the two reading procedures may be reciprocally related, as suggested by connectionist models (Harm \& Seidenberg, 1999; Plaut et al., 1996).

Long Term Development of Phonological and Orthographic Skills. In regard to accuracy scores in both reading and spelling, with two exceptions (the early lexicality effect noted in reading aloud and the fact that pseudowords were read as accurately as irregular words at the end of Grade 4), phonological processing was found to be more significant than orthographic processing throughout the study until the end, which contradicts the second hypothesis ${ }^{8}$. Similarly, according to the accuracy scores, the consistent effect of pseudohomophony observed in the semantic categorization task was not consistent with the second hypothesis. Given that, in the orthographic choice task, the level of accuracy was very high from the end of Grade 2 until the end of the study and that the shape of the original real words was less well preserved in the pseudohomophones than in the visual foils, the phonological features of the items appeared to have a long lasting influence on the silent reading performance of the children, even for words that seem to already be part of their orthographic lexicon. This result is especially significant as the effect of homophony was obtained under the circumstances that are the least conducive to it; the words from which foils were derived were frequent; the orthographic overlap between the correct exemplar and the pseudohomophone was low; we relied on narrow categories which allow the target word to be generated prior to its presentation; and the pseudohomophones were not lexical units (see Coltheart, Patterson, \& Leahy, 1994; 
Jared \& Seidenberg, 1991; Peter \& Turvey, 1994; Van Orden, 1987; Van Orden, Johnston, \& Hale, 1988).

Some findings were, however, in agreement with the second hypothesis that orthographics would be more important than phonological processing at the later ages. First, in reading aloud, a very early effect of lexicality effect was observed in the comparison between regular words and pseudowords (in accuracy scores from the end of Grade 1, and in processing time as soon as it could be taken into account, i.e. the end of Grade 2). Second, no regularity effect was found in the comparison between regular and irregular words, but only according to processing time from the end of Grade 3. Third, the lexicality effect surpassed the regularity effect in the comparison between pseudowords and irregular words from the end of Grade 3, but still only in processing time. Fourth, the effect of pseudohomophony did not produce slower times for correct pseudohomophone rejection at the end of Grade 4, again only in processing time. However, the latency data from reading aloud and silent reading do not necessarily indicate reliance on an orthographic procedure.

In a semantic categorization task relying on the effect of pseudohomophony, the cognitive system faces two conflicting responses, that of the visual route saying "no" and that of the phonological route saying "yes" (see Frost, 1998). This should result in more false positive responses and slower time responses for pseudohomophones than for visual foils; this is exactly the result observed in the present study. In reading aloud, latencies capture not only reliance on a sequential sublexical procedure or on a lexical orthographic procedure, but also the effect of articulatory codes which are more encapsulated for words than for pseudowords (see Marmurek \& Rinaldo, 1992; Rastle, Harrington, Coltheart, \& Palethorpe, 2000). This could explain why regular words were processed more rapidly than pseudowords. The implication of articulatory codes may also explain why, when the regularity effect was significant for accuracy, the words read correctly, regular or not. The words were read at the same speed and the correctly read pseudowords were read less rapidly than the correctly read words. 


\section{Relation between Early Phonological Reading Skills and Later Orthographic Reading}

\section{Skills.}

The regression analyses indicated that, from the middle to the end of Grade 1, and from the end of Grade 1 to the end of Grade 4, orthographic skills were predicted by earlier phonological and earlier orthographic skills. However, from the middle of Grade 1 to the end of the study, only phonological skills significantly contributed to later orthographic skills. In addition, later phonological skills were only predicted by earlier phonological skills, the unique contribution of earlier orthographic skills being non-significant.

Given the asymmetry between the predictions for later orthographic skills compared to later phonological skills, the regression analyses suggested that very early reliance on phonological processing is a powerful generative mechanism, the efficiency of which is the main predictor of long-term reading skills, including orthographic skills. This result is consistent with the third hypothesis concerning the important role of phonological processing in the development of word-specific orthographic representations. However the results observed both from the middle to the end of Grade 1 and from the end of Grade 1 to the end of Grade 4 for the prediction of orthographic skills contradict this hypothesis, as orthographic skills were predicted by both phonological and orthographic skills.

\section{$\underline{\text { Tentative explanation }}$}

The larger increase observed for regular words compared to pseudowords or to irregular words in the beginning of reading acquisition could be explained by the fact that the regular words in this study were frequent, thus benefiting from both a word frequency and a graphemephoneme regularity advantage whereas irregular frequent words or pseudowords benefited from only one of these effects. However, irregular words always contain some regular graphemephoneme correspondences. The difficulties in reading irregular words may thus depend on word frequency, but also, at least partially, on grapheme-phoneme regularity. For example, the use of high-frequency French grapheme-phoneme correspondences leads to the pronunciation 
of the high-frequency word "femme" as /FEM/. Knowing that this word does not exist, but that the word /FAM/ does, children can infer that "e" is read /A/ in this word.

Children may learn most of the relations between orthography and phonology through this implicit procedure. The strength of the associations, depending on both grapheme-phoneme regularity and word frequency, enabled the gradual construction of the orthographic lexicon. Thus, beginning readers would rely first on sublexical phonological processing which would enable them to gradually abstract the statistical relations between sublexical orthographic units and sublexical phonological units, allowing novel words to be read through generalization of this knowledge. In a few months, new connections would be created between phonological and orthographic units, probably at a lexical level. This could explain the results observed in the multiple regression analyses showing orthographic skills, explained, in the long-term, only by very early phonological skills. The fact that, in the short-term, particularly in the beginning of the study, both phonological and orthographic skills contributed to later orthographic skills, suggests that some part of the orthographic lexicon could be in place very early. However, these very early orthographic skills may not have the same underlying structure as the later orthographic skills.

Another shift was observed when examining the predictors of phonological skills. Late phonological skills were only predicted by earlier phonological skills, but the long-term predictive value of very early phonological skills, although significant, was low. This was not the case when examining the impact of very early phonological skills on early phonological skills, or of early phonological skills on later phonological skills. These data may be explained by a progressive change in the nature of the units on which the phonological procedure relies. It is possible that, at least in French and according to the characteristics of French orthography (for a brief presentation, see Sprenger-Charolles et al., 1998b), beginning readers first rely on surface units (the letters), soon after on graphemes (see Sprenger-Charolles \& Casalis, 1995; Sprenger-Charolles et al., 1998b) and, later, on larger sublexical units, the syllable being a possible candidate (see Colé, Magnan, \& Grainger, 1999). 
The simple explanation that we propose makes clear the course of the development of word reading skills observed in the present study. It may also explain why, due to the strong asymmetry between grapheme-phoneme and phoneme-grapheme correspondences in French (Peereman \& Content, 1999) and in English (Kessler \& Treiman, 2001), reading acquisition is easier than spelling acquisition ${ }^{9}$ (for French children, the present study, see also Alegria \& Mousty, 1996; Leybaert \& Content, 1995; Sprenger-Charolles \& Casalis, 1995; for English children, Bruck \& Waters, 1988; Foorman et al., 1991, 1993; Juel, 1988; Juel et al., 1986; Lennox \& Siegel, 1993; Stage \& Wagner, 1992). More generally, it may explain why reading is easier in shallow than in deeper orthographies. For example, in French, grapheme-phoneme correspondences are more consistent than in English and the reading results of Englishspeaking adults (see Paulesu, Démonet, Fazio, McCrory, Chanoine, Brunswick, Cappa, Cossu, Habib, Frith, \& Frith, 2001), as well as those of English-speaking children (Bruck, Genesee, \& Caravolas, 1997; Goswami, Gombert, \& Barrera, 1998) were found to be inferior to those of French-speaking subjects.

In conclusion, the present results provide insight into the development of written word processing in French, a language for which long-term longitudinal data were not previously available. More generally, they also provide insight into reading models, even though most of the models were mainly developed for the processing of English monosyllabic words. Our results suggest that at the very beginning, phonological decoding skills could be the necessary basis for the development of reading skills, thus supporting Share (1995, 1999), Ehri (1998) and Perfetti's (1992) hypotheses on the role of phonological processing in reading development. In addition, signs of reliance on the phonological procedure were still found to be present when indicators of reliance on the orthographic procedure appeared, suggesting a lack of a clear developmental shift from one procedure to the other, at least during the periods studied here. These results are not consistent with stage models such as those of Frith (1986) and Morton (1989). Moreover, as the phonological and orthographic procedures seem to continue to develop and be recruited in varying degrees depending on the task and on the item's specificities, these two procedures could be reciprocally related, rather than independent 
components of written word recognition, as assumed by connectionist models (see for example, Harm \& Seidenberg, 2001) unlike in Coltheart et al.'s dual route model (2001).

It should also be noted that the impact of phonology in written word processing observed in the present study could have been underestimated, as suggested by studies using brief presentation paradigms which showed that phonological processes were fast, automatic and general, both in expert readers (Perfetti \& Bell, 1991) and in children (Booth, Perfetti, \& MacWhinney, 1999) and that reliance on this processing increased as a function of age and reading expertise (Booth et al., 1999) whereas reliance on semantic processing decreased (Plaut \& Booth, 2000). However when reading is slow and even more so when accuracy is low, tasks such as those that rely on brief exposure are difficult to use because they require automaticity. At the very beginning of reading acquisition, even a silent reading task, such as our semantic decision task, is problematic. This kind of difficulty constitutes a problem for longitudinal studies that attempt to elucidate the mechanisms involved from the very beginning of reading-spelling acquisition to the expert stage. 
NOTE 1. These results might have been due to differences in orthographic consistency, as well as to differences in instructional approach, the two factors being interrelated. Consistent orthography lends itself to systematic teaching by a phonic method, whereas inconsistent orthography demands more complex methods.

NOTE 2. We relied on the concept of regularity, and not on the concept of consistency as defined by Glushko (1979) or by Plaut et al. (1996) because consistency is primarily relevant for the processing of monosyllabic items, which represent only a small percentage of words in French $(6.70 \%$ of the words in the Micro Robert, 1986, see Content, Mousty, \& Radeau, 1990).

NOTE 3. At the beginning of the study, all the children of 7 kindergarten classes, that is almost 140 children, were included. We had parental agreement for about $75 \%$. We first eliminated the children who spoke a language other than French at home (around 12\%). We then eliminated those who had language or motor problems or psychological difficulties according to the teachers or school psychologists (around 3\%). We next eliminated those whose non-verbal IQ was under the $25^{\text {th }}$ percentile as well as those whose verbal IQ was more than one standard deviation under the mean of the sample (around 10\%). Finally, we eliminated the children who could be considered readers at the end of kindergarten (approximately 10\%). There were almost 60 children in the beginning of Grade 1, and due to some losses there were 48 at the end of Grade 2 and 42 at the end of Grade 4.

NOTE 4. Irregular words were chosen following the frequency count of graphemes by Catach (1980). This count has recently been corroborated by MANULEX (Lété, SprengerCharolles, \& Colé, submitted), a lexical database that was not available at the time this study was conducted. MANULEX provides frequency based lists of words computed from the 1.9 million words of the main French readers, for four levels: $1^{\text {st }}$ Grade, $2^{\text {nd }}$ Grade, $3^{\text {rd }}$ to $5^{\text {th }}$ Grades, and for all Grades. The grapheme-phoneme correspondences used in the present study which had been defined as rare by Catach are also rare in MANULEX. If only the MANULEX $1^{\text {st }}$ Grade corpus is taken into account, for the vocalic grapheme-phoneme correspondences used in the present study, "oê" appears only in the test-word "poêle" and is pronounced /WA/, which is usually spelled "oi"; "oeu" is in the test-word "noeud" and in only 6 other items, the most 
frequent grapheme for / $\varnothing /$ being "eu" (as in "jeudi" [Thursday]); "oë" is in the test-word "noël" and in only two other words, /O+E/ being usually written "oé" or "oè" (as in "poésie" [poetry] versus "poète" [poet]). Other vocalic grapheme-phoneme correspondences depend on the following consonants. For example, "e" followed by a double consonant is read /E/, except in the test-word "femme" and in one other word; at the end of a word, "u+m" is pronounced /OM/, as in the test-word "album" and in only 3 other words, but not in "parfum" [perfume]; the letter "e" followed by "d" as the final letter of a word is only found in the test-word "pied", pronounced /PIE/. Concerning the grapheme-phoneme correspondences for the consonants used in the present study, "t" is usually pronounced /T/, except when followed by "ion(s)"; in that case the "t" is pronounced /S/ as in the test-words "attention" and "punition" and in 10 other words; however, "t" is pronounced /T/ when the preceding letter is "s", as in "question", and when "ions" is the end of a verb ("nous étions" [we were]). The grapheme "p" is silent before "t" in the test-words "compte" and "sept" and their derivatives, except in "septembre", but is pronounced in 4 other words. When "sc" begins a word, the "c" is either silent as in the test-word "scie" and in 4 other words or is pronounced in other words. Finally, "sh" is a very rare grapheme (the corresponding phoneme being usually written "ch"), only found in the test-word "short" and in one other word, but this grapheme is pronounced /Z/ in the middle of the word "déshabiller" (to undress). Given all these characteristics, it seems that our irregular words could not easily benefit from orthographic neighbourhood.

NOTE 5. In the first stage of this longitudinal study, we took word frequency into account (Sprenger-Charolles et al., 1998b). Frequency was defined according to the "Listes Orthographiques de Base" (LOB, Catach, 1984), which uses several frequency tables (Juilland, Brodin, \& Davidovitch, 1970; Gougenheim, Michéa, Rivenc, \& Sauvageot, 1964; Trésor de la langue française, 1971). However, to avoid the use of low frequency words, which would be, in fact, pseudowords for the children, we only selected words that were known by first graders. Word familiarity was assessed by an oral examination of children of the same age and school level as those tested in this study. In the present study, we did not take word frequency into account because very young children knew even our low frequency words. It should also to be 
noted that, in the first stage of this study (Sprenger-Charolles et al, 1998b), both in reading and in spelling, the effect of frequency, when significant (only at the end of Grade 1) was small (around 10\%).

NOTE 6. In reading aloud, in order to conduct the ANOVAs for time latencies in the same way as those for accuracy, we included the results of a small number of children whose accuracy scores were lower than $50 \%$. This was the case, at the end of Grade 2 , for 7 children in irregular word reading (the scores of 4 of them being higher than $40 \%$ ) and, at the end of Grade 4, for one child in pseudoword reading. Similarly, for the semantic categorization task, we included the results of some children who produced less than $50 \%$ of correct responses for phonological and visual foils ( 6 and 3 children respectively).

NOTE 7. Nonverbal IQ was assessed with Raven's matrices (Raven, 1981) and verbal IQ with an oral French vocabulary test (Deltour \& Hupkens, 1980). For the analyses, we used the mean percentage of correct responses for these two tests $(57.5, \underline{S D}=6.9)$. It should be noted that only children who were not able to read at the end of kindergarten were enrolled in the study.

NOTE 8. The incidence of more successful processing of pseudowords than irregular words could also be due to (1) the former having a higher number of orthographic neighbors than the latter or (2)the irregular words' greater orthographic complexity. These two explanations are not compatible with our data since, first, our pseudowords were not analog to frequent words and, second, their trigraph frequency (72) was not higher than that of the irregular words (221).

NOTE 9. In the present study, the same items were first presented in reading aloud and, after, in spelling. This procedure might cause some priming on the spelling task, which might therefore overestimate spelling abilities. In spite of this, the spelling scores, particularly for the words, were lower than the reading scores (see table 1). 


\section{REFERENCES}

Alegria, J., \& Mousty, P. (1996). The development of spelling procedures in French-speaking, normal and reading disabled children: Effects of frequency and of lexicality. Journal of Experimental Child Psychology, 63, 312-338.

Backman, J., Bruck, M, Hebert, M., \& Seidenberg, M. S. (1984). Acquisition and use of spelling sound correspondences in reading. Journal of Experimental Child Psychology, $\underline{38}, 114-$ 133.

Béchennec, D., \& Sprenger-Charolles, L. (1998). Literacy teaching in France. In D. Corson (Ed.), Encyclopedia of Language and Education (vol. 2, pp. 191-198). Dordrecht: Kluwer Academic Press.

Booth J. R., Perfetti, C. A., \& MacWhinney, B. (1999). Quick, automatic and general activation of silent word reading and phonological representations in young readers. Developmental Psychology, 35, 3-19.

Bosman, A. M. T., \& de Groot, A. M. B. (1996). Phonological mediation is fundamental to reading: Evidence from beginning readers. The Quarterly Journal of Experimental Psychology, 49A, 715-744.

Bruck, M., Genesee, F., \& Caravolas, M. (1997). A cross linguistic study of early literacy acquisition. In B. Blachman (Ed.), Foundations of Reading Acquisition and Dyslexia:

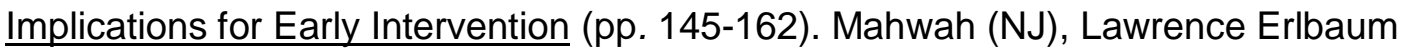
associates.

Bruck, M., \& Waters, G. S. (1988). An analysis of spelling errors of children who differ in their reading skills. Applied Psycholinguistics, $\underline{9}$, 77-92.

Byrne, B., Freebody, P., \& Gates, A. (1992). Longitudinal data on the relations of word-reading strategies to comprehension, reading time and phonemic awareness. $\underline{\text { Reading Research }}$ Quarterly, 27, 141-151.

Catach, N. (1980). L'orthographe français: Traité théorique et pratique. Paris: Nathan. 
Catach, N. (1984). Les listes orthographiques de base (LOB): Les mots les plus fréquents et leurs formes fléchies les plus fréquentes. [Basic orthographic lists: High frequency words and their most frequent flexional forms]. Paris: Nathan.

Colé, P., Magnan, A., \& Grainger, J. (1999). Syllable-sized units in visual word recognition: Evidence from skilled and beginning readers of French, Applied Psycholinguistic, 20, 507532.

Coltheart, M., Rastle K., Perry C., Langdon R., \& Ziegler J. (2001). DRC: A dual route cascaded model of visual word recognition and reading aloud. Psychological Review, 108, 204-256.

Coltheart, V., Laxon, V., Rickard, M., \& Elton, C. (1988). Phonological recoding in reading for meaning by adults and children. Journal of Experimental Psychology: Learning, Memory and Cognition, 14, 387-397.

Coltheart, V., Patterson, K., Leahy, J. (1994). When a rows is a rose: Phonological effects in written word comprehension. Quarterly Journal of Experimental Psychology, 47, 917-955

Content, A., \& Radeau, M. (1988). Données statistiques sur la structure orthographique du Français. Cahiers de Psychologie Cognitive/ European Bulletin of Cognitive Psychology. Special issue, 87p.

Content, A., Mousty, P., \& Radeau, M. (1990). Brulex: une base de données lexicales informatisée pour le Français écrit et parlé. Année Psychologique, 90, 551-566.

Deltour, J. J., \& Hupkens, D. (1980). Test de vocabulaire actif et passif pour enfants (5 à 8 ans). Issy-les-Moulineaux, E.A.P.

Doctor, E., \& Coltheart M. (1980). Phonological recoding in children's reading for meaning. Memory and Cognition, $\underline{80}$, 195-209.

Ehri, L. C. (1998). Grapheme-phoneme knowledge is essential for learning to read words in English. In J. L. Metsala, \& L. Ehri (Eds.), Word recognition in beginning literacy (pp. 340). Mahwah, NJ: Erlbaum.

Ehri, L., \& Wilce, L.S. (1985). Movement into reading: Is the first stage of printed word learning visual or phonetic? Reading Research Quarterly, 20163-179. 
Foorman, B. R., Jenkins, L., \& Francis, D. J. (1993). Links between segmenting, spelling and reading words in first and second grades. Reading and Writing: An Interdisciplinary Journal, $\underline{5}, 1-15$.

Foorman, B. R., Novy, D. M., Francis, D. J., \& Liberman, D. (1991). How letter-sound instruction mediates progress in first grade reading and spelling. Journal of Educational Psychology, $\underline{83}, 4,456-469$.

Frith, U. (1986). A Developmental framework for developmental dyslexia. Annals of Dyslexia, $\underline{36}, 69-81$.

Frost, R. (1998). Toward a strong phonological theory of visual word recognition: True issues and false trails. Psychological Bulletin, $\underline{123}, 71-99$.

Glushko, R. (1979) The organisation and synthesis of orthographic knowledge in reading aloud. Journal of Experimental Psychology: Human Perception and Performance, $\underline{5}$, 674-691.

Goswami, U., Ziegler, J., C., Dalton,L., \& Schneider, W. (2001). Pseudohomophone effects and phonological recoding procedures in reading development in English and German. Journal of Memory and Language, $\underline{45}, 648-664$.

Goswami, U., Gombert, J. E., \& Barrera, L. F. (1998). Children's orthographic representations and linguistic transparency: nonsense word reading in English, French and Spanish. Applied Psycholinguistics, 19,19-52.

Gougenheim, G., Michéa, R., Rivenc, P., \& Sauvageot, A. (1964). L'élaboration du français $\underline{\text { fondamental ( } 1^{\mathrm{er}} \text { degré): Etude sur l'établissement d'un vocabulaire et d'une grammaire }}$ de base. [Learning basic French (first level): A study on setting-up a basic vocabulary and grammar]. Paris: Didier.

Harm, M. W., \& Seidenberg, M. S. (1999). Phonology, reading acquisition, and dyslexia: Insights from connectionist models. Psychological Review, 106, 491-528.

Harm, M. W., \& Seidenberg M. S. (2001). Are there orthographic impairments in phonological

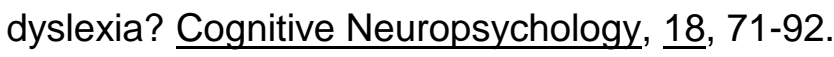

Jared, D., \& Seidenberg, M.S. (1991). Word identification proceeds from spelling to sound to meaning. Journal of Experimental Psychology: General, 120, 358-394. 
Johnston, R. S., Thompson, G. B., Fletcher-Flinn, C. M., \& Holligan, C. (1995). The functions of phonology in the acquisition of reading: Lexical sentence processing. Memory \&

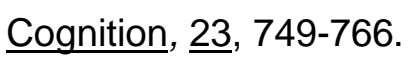

Juel, C. (1988). Learning to read and write: A longitudinal study of 54 children from first through fourth grade. Journal of Educational Psychology, $\underline{80}, 437-447$.

Juel, C., Griffith, P. L., \& Gough, P. B. (1986). Acquisition of literacy: A longitudinal study of children in first and second grade. Journal of Educational Psychology, 78, 243-255.

Juilland, A., Brodin, D., \& Davidovitch, C. (1970). Frequency dictionary of French words. La Haye. Mouton.

Kessler, B., \& Treiman, R. (2001). Relationships between sounds and letters in English monosyllables. Journal of Memory and Language, $\underline{44}, 592-617$.

Laing, E., \& Hulme, C. (1999). Phonological and semantic processes influence beginning readers' ability to learn to read words. Journal of Experimental Child Psychology, $\underline{73}, 183-$ 207.

Lennox, C., \& Siegel, L.S. (1993). Visual and phonological spelling errors in subtypes of children with learning disabilities. Applied Psycholinguistics, 14, 473-488.

Lété, B., Sprenger-Charolles, L., \& Colé, P. (submitted). MANULEX: A lexical database from French readers.

Leybaert, J., \& Content, A. (1995). Reading and spelling acquisition in two different teaching methods: A test of the independence hypothesis. Reading and Writing: An Interdisciplinary Journal, $\underline{7}, 65-88$.

Manis, F. R., Seidenberg, M. S., \& Doi, L. M. (1999). See Dick RAN: Rapid naming and the longitudinal prediction of reading subskills in first and second graders. Scientific Study of Reading, 3, 129-157.

Manis, F. R., Custodio, R., \& Szeszulski, P.A. (1993). Development of phonologic and orthographic skills: A 2-year longitudinal study of dyslexic children. Journal of Experimental Child Psychology, $\underline{56}, 64-86$. 
Marmurek, H. H. C., \& Rinaldo, R. (1992). The development of letter and syllable effects in categorization, reading aloud and picture naming. Journal of Experimental Child Psychology, 53, 277-299.

Morton, J. (1989). An Information-processing account of reading acquisition. In A. M. Galaburda (Ed.), From Reading to Neurons (pp. 43-66). Cambridge, MA: Bradford Book, MIT Press.

Olson, R., Forsberg, H., Wise, B., \& Rack, J. (1994). Measurement of word recognition, orthographic and phonological skills. In G. R. Lyon (Ed.), Frames of reference for the assessment of learning disabilities: New views on measurement issues (pp. 243-275). Baltimore: Brookes.

Paulesu, E., Démonet, J. F., Fazio, F., McCrory, E., Chanoine, V., Brunswick, N, Cappa, S. F., Cossu, G., Habib, M., Frith, C. D., Frith, U. (2001). Dyslexia, cultural diversity and biological unity. Science, $\underline{291}, 2165-2167$.

Peereman, R., \& Content, A. (1999). LEXOP: A lexical database providing orthographyphonology statistics for French monosyllabic words. Behavioral Methods, Instruments and Computers, $\underline{31}, 376-379$

Perfetti, C. (1992). The representation problem in reading acquisition. In P. Gough, L. Ehri, \& R. Treiman (Eds.), Reading Acquisition (pp. 107-143). Hillsdale, NJ: Erlbaum.

Perfetti, C. A., \& Bell, L. (1991). Automatic phonemic activation in silent word reading. Evidence for backward masking. Journal of Memory and Language, 27, 59-70.

Peter, M., \& Turvey, M. T. (1994). Phonological codes are early sources of constraint in visual semantic categorization. Perception and Psychophysics, $\underline{55}$, 497-504.

Plaut, D. C., \& Booth J. R. (2000). Individual and developmental differences in semantic priming: Empirical and computational support for a single mechanism account of lexical processing. Psychological Review, 107, 786-823.

Plaut, D. C., McClelland, J. L., Seidenberg, M. S., \& Patterson, K. E. (1996). Understanding normal and impaired word reading: Computational principles in quasi-regular domain. Psychological Review, 103, 56-115. 
Rack, J., Hulme, C., Snowling, M.J., \& Wightman, J. (1994). The role of phonology in young children learning to read words: The direct mapping hypothesis, Journal of Experimental Child Psychology, 57, 42-71.

Rastle, K., Harrington, J., Coltheart, M., \& Palethorpe, S. (2000). Reading aloud begins when the computation of phonology is complete. Journal of Experimental Psychology: Human Perception and Performance. $\underline{26}, 1178-1191$.

Raven (1947, réed. 1981). Progressives Matrices Standard. Issy-les-Moulineaux: E.A.P.

Robert, P., (1986). Micro-Robert. Dictionnaire du français primordial, nouvelle édition revue et mise à jour. Paris: Dictionnaires le Robert.

Savigny, M. (1974). Manuel (forme B) pour l'utilisation des tests BAT-ELEM. Issy les Moulineaux: E.A.P.

Seidenberg, M. S., \& McClelland, J. L. (1989). A distributed developmental model of word recognition and naming. Psychological Review, 96, 523-568.

Seidenberg, M. S., Waters, G. S., Barnes, M. A., \& Tanenhaus, M. K. (1984). When does irregular spelling or pronunciation influence word recognition? Journal of Verbal Learning and Verbal Behavior, 23, 383-404.

Share, D. L. (1995). Phonological recoding and self-teaching: Sine qua non of reading acquisition. $\underline{\text { Cognition, }}$ 55, 151-218.

Share, D. L. (1999). Phonological recoding and orthographic learning: a direct test of the selfteaching hypothesis. Journal of Experimental Child Psychology, 72, 95-129.

Sprenger-Charolles, L. (2003). Reading acquisition: Cross linguistic data. In T.Nunes and P.Bryant (Eds.), Handbook of children's literacy. Kluwer Academic Publishers b.v. Sprenger-Charolles, L., \& Casalis, S. (1995). Reading and spelling acquisition in French first graders: Longitudinal evidence. Reading and Writing: An Interdisciplinary Journal, $\underline{7}, 1-25$.

Sprenger-Charolles, L., Siegel, L. S., \& Béchennec, D. (1998a). Phonological mediation and semantic and orthographic factors in silent reading in French. Scientific Studies of Reading, 2, 3-29. 
Sprenger-Charolles, L., Siegel, L. S., \& Bonnet, P. (1998b). Phonological mediation and orthographic factors in reading and spelling. Journal of Experimental Child Psychology, $\underline{68}, 134-155$.

Stage, S. A., \& Wagner, R. K. (1992). Development of young children's phonological and orthographic knowledge as revealed by their spellings. Developmental Psychology, $\underline{28}$, 287-296.

Trésor de la langue française (1971). Nancy : Centre National de la Recherche Scientifique. Van Orden, G. C. (1987). A ROWS, is a ROSE: Spelling, sound and reading. Memory and $\underline{\text { Cognition, }}$ 15, 181-198.

Van Orden, G. C., Johnston, J. C., \& Hale, B. L. (1988). Word identification in reading proceeds from spelling to sound to meaning, Journal of Experimental Psychology: Learning. Memory and Cognition, $14,371-386$

Waters, G. S., Bruck, M., \& Seidenberg, G. M. S. (1985). Do children use similar processes to

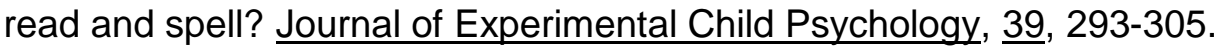

Waters, G. S., Seidenberg, G. M. S., \& Bruck, M. (1984). Children's and adults' use of spelling sound information in three reading tasks. Memory \& Cognition, $\underline{12}, 293-305$.

Wimmer, H., \& Hummer, P. (1990). How German speaking first graders read and spell: Doubts on the importance of the logographic stage. Applied Psycholinguistics, 11, 349-368.

Ziegler, J., Jacobs, A., \& Stone G. (1996). Statistical analysis of the bi-directional inconsistency of spelling and sound in French. Behavior, Method, Research, Instruments and Computer, $\underline{28}, 504-515$

Ziegler, J., Stone, G., \& Jacobs, A. (1997). What's the pronunciation for -OUGH and the spelling for /u/? Database for computing feedforward and feedback inconsistency in English. Behavior, Method, Research, Instruments and Computer, 29, 600-618. 
Appendix

ITEMS USED FOR THE READING ALOUD AND SPELLING TASKS

$\underline{\text { Irregular words }}{ }^{4}$ : $\left(\mathrm{a}^{*}\right)$ pied (foot), punition (punishment), poêle (frying pan), compte (count); ( $\mathrm{b}^{*}$ ) noël (Christmas), noeud (knot); (c*) femme (woman), sept (seven), scie (saw), short (shorts); $\left(\mathrm{e}^{\star}\right)$ attention (attention), album (album).

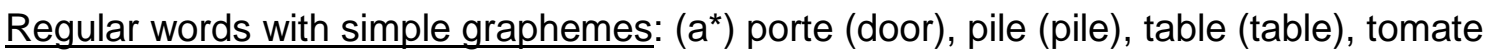
(tomato); ( $\left.b^{\star}\right)$ minute (minute), marmite (pot); (c*) samedi (Saturday), sable (sand); ( $\left.d^{\star}\right)$ livre (book), lavabo (basin); ( $\left.\mathrm{e}^{\star}\right)$ arbre (tree), abri (shelter).

Regular words with digraphs: $\left(a^{*}\right)$ poche (pocket), poudre (powder), tour (tour), tache (mark); $\left(b^{\star}\right)$ marche (step), moule (mussel/mould); (c*) four (oven), sourire (smile); (d*) riche (rich), ruche (hive); ( $e^{\star}$ ) ouvre (open), écharpe (scarf).

$\underline{\text { Regular words with contextual graphemes: }}\left(\mathrm{a}^{*}\right)$ page (page), partage (share), plage (beach), potage (soup); ( $\left.b^{\star}\right)$ merci (thank you), noirci (darkened); ( $\left.c^{\star}\right)$ facile (easy), figue (fig); ( $d^{\star}$ ) longue (long), local (local); (e*) école (school), acide (sour).

Pseudowords (first consonant: stop, nasal, fricative, liquid)

Pseudowords with simple graphemes: tanepi, mirpe, sinope, lople;

Pseudowords with digraphs: turche, moube, sulche, loumi;

Pseudowords with contextual graphemes: tocir, marpige, silge, lurce.

Note: * First phoneme: (a) Stop consonant, (b) Nasal, (c) Fricative, (d) Liquid, (e) Vowel 
ITEMS USED FOR THE SEMANTIC CATEGORIZATION AND ORTHOGRAPHIC CHOICE

TASKS

$\begin{array}{llll}\text { Category } & \text { Foils } & & \text { Correct exemplar } \\ \text { Animals } & \text { Homophone } & \text { Visual } & \\ & \text { lou } & \text { louq } & \text { loup (wolf) } \\ \text { Colors } & \text { rouje } & \text { pigean } & \text { pigeon (pigeon) } \\ & \text { blan } & \text { rouqe } & \text { rouge (red) } \\ \text { Fruits \& } & \text { frèze } & \text { blauc } & \text { blanc (white) } \\ \text { Vegetables } & \text { pome } & \text { froise } & \text { fraise (strawberry) } \\ & \text { carote } & \text { pomne } & \text { pomme (apple) } \\ \text { Means } & \text { trin } & \text { caratte } & \text { carotte (carrot) } \\ \text { of Transport } & \text { oto } & \text { troin } & \text { train (train) } \\ & \text { vélau } & \text { outo } & \text { auto (car) }\end{array}$

Filler lists : (Semantic task only)

List 1: lapin (rabbit), chien (dog), gris (gray), noir (black), jaune (yellow), poire (pear), salade (salad), purée (mashed potatoes), soupe (soup), moto (motorcycle), bol (bowl), manteau (coat), chemise (shirt), Bruno (proper name).

List 2: chat, (cat), vache, (cow), bleu, (blue), tomate (tomato), banane (banana), prune (plum), pêche (peach), avion (plane), bus (bus), couteau (knife), verre (glass), pantalon (trousers), tulipe (tulip), Luc (proper name). 
Table 1.

Mean Percentage of Correct Responses (and Standard Deviations) for the Reading and Spelling Tasks

Task

Grade

1-Middle 2-End 2-End 3-End

Reading

Regular words

$43.25(30.48) \quad 89.48(22.11)$

$95.24(05.89)$

$96.49(04.76)$

$97.55(04.72)$

Irregular words

$05.36(06.06)$

38.29 (27.18)

70.63 (18.88)

83.53 (13.46)

89.68 (12.18)

Pseudowords

$49.70(33.19)$

74.40 (28.01)

$83.73(15.17)$

$89.68(11.01)$

$90.28(13.39)$

Spelling

Regular words

40.38 (30.28)

74.50 (22.09)

78.77 (14.28)

87.83 (10.21)

$92.46(06.62)$

Irregular words

04.37 (04.60)

13.69 (14.12)

41.07 (20.11)

65.28 (19.90)

74.60 (22.16)

Pseudowords

47.92 (33.92)

$76.19(25.42)$

85.71 (12.52)

91.07 (09.28)

$92.26(10.48)$ 
Table 2

Mean Time Latencies for Correct Responses (and Standard Deviations) for the Reading Tasks (milliseconds)

Grade 2-End Grade 3-End Grade 4-End

$\begin{array}{lccc}\text { Regular words } & 1083(445) & 829(304) & 799(220) \\ \text { Irregular words } & 1192(583) & 837(304) & 812(298) \\ \text { Pseudowords } & 1225(422) & 1064(313) & 1089(393)\end{array}$




\section{Table 3}

Mean Number of Correct Responses for Phonological and Visual Foils in the Semantic Categorization Task (Maximum $=10$ ) and Mean Percentage of Correct Responses in the Orthographic Choice Task

Task

Grade

1-Middle 2-End 2-End $\quad 3$-End

Semantic Categorization Task

Pseudohomophones

$01.31(01.37)$

$00.93(01.50)$

02.48 (02.72)

05.38 (03.26)

$07.55(02.64)$

Visual Foils

01.71 (01.73)

$02.95(02.16)$

$04.81(03.11)$

07.05 (02.66)

$08.26(02.18)$

Orthographic Choice Task

$39.76(15.06)$

65.00 (19.41)

$85.95(17.4)$

89.05 (13.22)

$92.14(09.76)$ 
Table 4.

Correlations Among the Tasks

$\begin{array}{llllll}1 & 2 & 3 & 4 & 5 & 6 \\ 7 & & & & & \end{array}$

1. Kindergarten Verbal and Non-Verbal IQs

2. Grade 1 (Middle) Irregular word reading $\quad .24$

3. Grade 1 (Middle) Pseudoword reading $\quad .23 \quad .46^{\star *}$

4. Grade 1 (End) Irregular word reading $\quad .29 \quad .55^{\star *} \quad .56^{\star *}$

$\begin{array}{llllll}\text { 5. Grade } 1 \text { (End) Pseudoword reading } & .13 & .14 & .53^{\star *} & .54^{\star *}\end{array}$

6. Grade 4 (End) Irregular word reading $\quad .17 \quad .29 \quad .41^{\star *} \quad .50^{\star *} \quad .50^{\star *}$

$\begin{array}{lllllll}\text { 7. Grade } 4 \text { (End) Pseudoword reading } & .17 & .24 & .39^{* *} & .52^{* *} & .64^{* *} & .62^{* *}\end{array}$

Note: ${ }^{*}$ for $\underline{p}<.05 ;{ }^{* *}$ for $\underline{p}<.01$ 


\section{Table 5}

Hierarchical Regression Analyses Predicting Reading Irregular Word and Pseudoword Accuracy at the end of Grades 1 and 4, Including Commonality Analysis

$\begin{array}{ll}\text { Irregular word } & \text { Pseudoword } \\ \text { Grade 1-End } \quad \text { Grade 4-End } & \text { Grade 1-End Grade 4-End }\end{array}$

Grade 1-Middle

Irregular Word and Pseudoword:

Common

Irregular word: Unique

Pseudoword word: Unique

Total variance
.193

$.104^{*}$

$.120^{* *}$

$.417^{* *}$
.070

.012

$.096^{*}$

$.178^{*}$
.006

.014

$.274^{\star \star}$

$.294^{\star *}$
.054

.004

$.101^{*}$

$.159^{*}$

Grade 1-End

Irregular Word and Pseudoword:

Common

Irregular word: Unique

Pseudoword word: Unique

Total variance
.174

.228

$.077^{*}$

$.072^{*}$

$.323^{* *}$
.044

$.183^{* *}$

$.455^{\star *}$

Note. ${ }^{*}$ for $\underline{p}<.05 ;{ }^{* *}$ for $\underline{p}<.01$ 